Original Articles

\title{
Monocarboxylate transport inhibition potentiates the cytotoxic effect of 5-fluorouracil in colorectal cancer cells
}

\author{
Ricardo Amorim a,b, Céline Pinheiro a,b,c,d, Vera Miranda-Gonçalves a,b, Helena Pereira e, \\ Mary P. Moyer ${ }^{\mathrm{f}}$, Ana Preto ${ }^{\mathrm{e}}$, Fátima Baltazar ${ }^{\mathrm{a}, \mathrm{b}, *}$ \\ ${ }^{a}$ Life and Health Sciences Research Institute (ICVS), School of Health Sciences, University of Minho, Braga, Portugal \\ b ICVS/3B's - PT Government Associate Laboratory, Braga/Guimarães, Portugal \\ ${ }^{\mathrm{c}}$ Molecular Oncology Research Center, Barretos Cancer Hospital, Barretos, Sao Paulo, Brazil

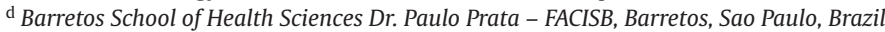 \\ e Centre of Molecular and Environmental Biology (CBMA)/Department of Biology, University of Minho, Braga, Portugal \\ ${ }^{\mathrm{f}}$ INCELL Corporation, San Antonio, TX, USA
}

\section{A R T I C L E I N F O}

\section{Article history:}

Received 7 February 2015

Received in revised form 29 April 2015

Accepted 10 May 2015

\section{Keywords:}

Colorectal cancer

Monocarboxylate transporters

Lactate transport

Glycolytic metabolism

5-Fluorouracil

\begin{abstract}
A B S T R A C T
Cancer cells rely mostly on glycolysis to meet their energetic demands, producing large amounts of lactate that are extruded to the tumour microenvironment by monocarboxylate transporters (MCTs). The role of MCTs in the survival of colorectal cancer (CRC) cells is scarce and poorly understood. In this study, we aimed to better understand this issue and exploit these transporters as novel therapeutic targets alone or in combination with the CRC classical chemotherapeutic drug 5-Fluorouracil.

For that purpose, we characterized the effects of MCT activity inhibition in normal and CRC derived cell lines and assessed the effect of MCT inhibition in combination with 5-FU.

Here, we demonstrated that MCT inhibition using CHC ( $\alpha$-cyano-4-hydroxycinnamic acid), DIDS (4,4'-diisothiocyanatostilbene-2,2'-disulphonic acid) and quercetin decreased cell viability, disrupted the glycolytic phenotype, inhibited proliferation and enhanced cell death in CRC cells. These results were confirmed by specific inhibition of MCT1/4 by RNA interference. Notably, we showed that 5-FU cytotoxicity was potentiated by lactate transport inhibition in CRC cells, either by activity inhibition or expression silencing.

These findings provide novel evidence for the pivotal role of MCTs in CRC maintenance and survival, as well as for the use of these transporters as potential new therapeutic targets in combination with CRC conventional therapy.
\end{abstract}

(C) 2015 Elsevier Ireland Ltd. All rights reserved.

\section{Introduction}

The distinct metabolic behaviour observed in tumour cells was recently recognized as a hallmark of cancer [1]. To support their energy demands, cancer cells increase the rates of glycolysis, leading to an overload of lactic acid, which must be exported to the extracellular milieu, decreasing extracellular $\mathrm{pH}$. This acidification contributes to the malignant phenotype of tumour cells, being associated with increased invasion [2], suppression of anti-cancer immune response [3], tumour proliferation, angiogenesis and metastasis [4,5]. Also, high extracellular lactate has been associated with poor prognosis in cancer patients $[5,6]$.

Monocarboxylate transporters (MCTs) are essential players in the maintenance of the glycolytic metabolism having a dual role, both as lactate transporters and $\mathrm{pH}$ regulators [7]. The MCT family

\footnotetext{
* Corresponding author. Tel.: +351 253 604828; fax: +351 253604820.

E-mail address: fbaltazar@ecsaude.uminho.pt (F. Baltazar).
}

presently comprises 14 members; however, only the first four (MCT1-4) are known to mediate the proton-coupled transport of monocarboxylic acids across the plasma membrane [8-14]. CD147 is a chaperone for both MCT1 and MCT4, promoting their correct plasma membrane expression and activity [15-18]. MCT inhibition disrupts both cellular and extracellular balance, namely affecting $\mathrm{pH}$ homeostasis, inducing apoptosis [19] and reducing tumour angiogenesis, invasion [20], and metastasis [21]. Several agents are known to inhibit MCT activity like $\alpha$-cyano-4-hydroxycinnamic acid (CHC), 4,4'-diisothiocyanatostilbene-2,2'-disulphonic acid (DIDS) and quercetin [22]. MCTs are currently seen as promising therapeutic targets in cancer, with encouraging results in various in vitro and in vivo studies $[13,23-30]$.

Data on the expression of MCTs in colorectal cancer (CRC) are scarce and contradictory [31-34]. Koukourakis et al. [31] found expression of MCT1 in cancer cells and in tumour-associated fibroblasts, while MCT4 was weakly expressed in the tumour environment. Conversely, our group [32] detected a significant gain in MCT1 and MCT4 membrane expression, compared with the adjacent normal 
epithelium. More recently [33,34], 50\% MCT4 plasma membrane positive staining in two cohorts of CRC patients was described, supporting the role of these MCT isoforms in CRC malignancy.

In the recent years, chemotherapeutic treatment of CRC suffered revolutionary changes, with new compounds and regimens approved or under investigation, namely the development of compounds targeting specific alterations in cell signalling pathways [35]. One of the most commonly used chemotherapeutic agents for the treatment of CRC is 5-fluorouracil (5-FU); however, there is growing evidence for 5-FU resistance [36]. When administered as a single agent, 5-FU activity is modest, with response rates of less than 10-15\% [37]. Efforts have been made to unravel new combinatory therapies aiming to enhance the therapeutic efficacy of 5-FU and reduce its side effects. Addition of leucovorin was shown to improve the efficacy of 5-FU with little toxicity [38] and, more recently, capecitabine (an orally administered prodrug of 5-FU) and newer monoclonal antibodies targeting the epidermal growth factor receptor (cetuximab and panitumumab) and the vascular endothelial growth factor (bevacizumab) have been introduced in CRC therapeutics [39-41].

The need for more effective therapeutic approaches led us to try to understand the role of MCTs in CRC cells and explore these transporters as therapeutic targets. Here, we assessed the role of MCTs on the viability, proliferation and energetic metabolism of CRC derived cell lines, and explored the potential of combining MCT inhibition with 5-FU. We observed that MCT activity inhibition inhibited cell viability and proliferation, disrupted the glycolytic phenotype, and enhanced cell death in CRC cells. These results were corroborated by MCT expression inhibition. Moreover, we showed that MCT inhibition potentiated the cytotoxic effect of 5-FU.

\section{Materials and methods}

Cell lines and culture conditions

The human colon carcinoma-derived cell lines HCT-15 and RKO were kindly provided by Dr. Raquel Seruca (IPATIMUP, Porto, Portugal). HCT-15 cells were cultured in RPMI 1640 medium (Gibco, Invitrogen, USA) supplemented with 10\% (v/v) fetal bovine serum (FBS, Gibco, Invitrogen, USA) and 1\% (v/v) penicillin-streptomycin solution (Pen/Strep, Invitrogen, USA). RKO cell line was grown in DMEM medium (Gibco, Invitrogen, USA) supplemented with $10 \%$ FBS and $1 \%$ Pen/Strep. The normalderived colon mucosa cell line NCM460 was obtained from INCELL Corporation upon MTA approval (LLC, San Antonio, USA). NCM460 cells were maintained in INCELL's enriched $\mathrm{M}^{\mathrm{TM}}$ Base medium supplemented with $10 \%$ FBS and 1\% Pen/Strep. All cell lines were incubated at $37^{\circ} \mathrm{C}$ in a $5 \% \mathrm{CO}_{2}$ humidified atmosphere.

Paraffin cytoblock preparation and immunocytochemistry

Paraffin cytoblocks of HCT-15, RKO and NCM460 cells were prepared and MCT1, MCT4 CD147 and GLUT1 protein expression was evaluated by immunocytochemistry, as previously described [30]. Detailed information is given in Table 1.

Western blot

MCT1, MCT4, CD147 and GLUT1 protein expression was evaluated by Western blotting, according to the conditions described in Table 2, as previously described [30].

\section{Chemicals}

Stock solutions of $\alpha$-cyano-4-hydroxycinnamic acid (CHC), 4,4'diisothiocyanatostilbene-2,2'-disulphonic acid disodium salt hydrate (DIDS), quercetin and 5-fluorouracil (5-FU) (Sigma-Aldrich, St. Louis, USA) were obtained by dissolution in 100\% dimethyl sulphoxide (DMSO, Sigma-Aldrich, St. Louis, USA). Working concentrations were obtained through dilutions in culture medium. The final concentration of DMSO was maintained at a maximum of $1 \%$. All controls were performed using DMSO alone (vehicle).

Cell viability and proliferation assays

Cell viability (biomass) was assessed by the Sulphorhodamine B (SRB) based In Vitro Toxicology Assay Kit (Sigma-Aldrich, St. Louis, USA) and cell proliferation was measured with the Cell Proliferation ELISA, BrdU (bromodeoxyuridine) colorimetric assay (Roche, Mannheim, Germany), as previously described [30].

Assessment of glucose and lactate levels

Extracellular levels of glucose (Roche, Germany) and lactate (SpinReact, Spain) were assessed by the enzymatic colorimetric kits, following the manufacturer's instructions.

Table 1

Details on the immunocytochemical procedure used to evaluate the expression of the different proteins.

\begin{tabular}{|c|c|c|c|c|c|c|}
\hline \multirow[t]{2}{*}{ Protein } & \multirow[t]{2}{*}{ Antigen retrieval } & \multirow[t]{2}{*}{ Positive control } & \multirow[t]{2}{*}{ Detection system } & \multicolumn{3}{|l|}{ Antibody } \\
\hline & & & & Company & Dilution & Incubation \\
\hline MCT1 & $\begin{array}{l}\text { Citrate buffer }(10 \mathrm{mM}, \mathrm{pH}=6.0) \\
98^{\circ} \mathrm{C} ; 20 \mathrm{~min}\end{array}$ & Colon carcinoma & $\begin{array}{l}\text { R.T.U. VECTASTAIN }{ }^{\circledR} \text { Elite }{ }^{\circledR} \text { ABC Kit } \\
\text { (Vector Laboratories) }\end{array}$ & $\begin{array}{l}\text { Chemicon } \\
\text { Ref. AB3538P }\end{array}$ & $1: 200$ & Overnight, $4^{\circ} \mathrm{C}$ \\
\hline MCT4 & $\begin{array}{l}\text { Citrate buffer }(10 \mathrm{mM}, \mathrm{pH}=6.0) \\
98^{\circ} \mathrm{C} ; 20 \mathrm{~min}\end{array}$ & Colon carcinoma & $\begin{array}{l}\text { Ultravision Detection System } \\
\text { Anti-polyvalent, HRP } \\
\text { (Lab Vision Corporation) }\end{array}$ & $\begin{array}{l}\text { Santa Cruz Biotechnology } \\
\text { Ref. sc-50329 }\end{array}$ & $1: 500$ & 2 hours, RT \\
\hline CD147 & $\begin{array}{l}\text { EDTA }(1 \mathrm{mM}, \mathrm{pH}=8) \\
98^{\circ} \mathrm{C} ; 15 \mathrm{~min}\end{array}$ & Colon carcinoma & $\begin{array}{l}\text { Ultravision Detection System } \\
\text { Anti-polyvalent, HRP } \\
\text { (Lab Vision Corporation) }\end{array}$ & $\begin{array}{l}\text { Zymed } \\
\text { Ref. 18-7344 }\end{array}$ & $1: 500$ & 2 hours, RT \\
\hline GLUT1 & $\begin{array}{l}\text { Citrate buffer }(10 \mathrm{mM}, \mathrm{pH}=6.0) \\
98^{\circ} \mathrm{C} ; 10 \mathrm{~min}\end{array}$ & Skin & $\begin{array}{l}\text { Ultravision Detection System } \\
\text { Anti-polyvalent, HRP } \\
\text { (Lab Vision Corporation) }\end{array}$ & $\begin{array}{l}\text { Abcam } \\
\text { Ref. ab15309-500 }\end{array}$ & $1: 500$ & 2 hours, RT \\
\hline
\end{tabular}

Table 2

Western-blot conditions to evaluate the expression of the different proteins.

\begin{tabular}{|c|c|c|c|c|c|c|}
\hline \multirow[t]{2}{*}{ Protein } & \multicolumn{3}{|l|}{ Primary polyclonal antibody } & \multicolumn{3}{|c|}{ Secondary antibody } \\
\hline & Company & Dilution & Incubation & Reactivity & Dilution & Incubation \\
\hline MCT1 & $\begin{array}{l}\text { Santa Cruz Biotechnology } \\
\text { Ref. sc-365501 }\end{array}$ & $1: 500$ & Overnight, $4{ }^{\circ} \mathrm{C}$ & Anti-mouse & $1: 5000$ & $45 \mathrm{~min}, \mathrm{RT}$ \\
\hline MCT4 & $\begin{array}{l}\text { Santa Cruz Biotechnology } \\
\text { Ref. sc-50329 }\end{array}$ & $1: 2000$ & Overnight, $4{ }^{\circ} \mathrm{C}$ & Anti-rabbit & $1: 5000$ & $45 \mathrm{~min}, \mathrm{RT}$ \\
\hline CD147 & $\begin{array}{l}\text { Santa Cruz Biotechnology } \\
\text { Ref. sc-71038 }\end{array}$ & $1: 200$ & Overnight, $4{ }^{\circ} \mathrm{C}$ & Anti-mouse & $1: 5000$ & $45 \mathrm{~min}, \mathrm{RT}$ \\
\hline GLUT1 & $\begin{array}{l}\text { Abcam } \\
\text { Ref. ab15309-500 }\end{array}$ & $1: 800$ & Overnight, $4{ }^{\circ} \mathrm{C}$ & Anti-rabbit & $1: 5000$ & $45 \mathrm{~min}, \mathrm{RT}$ \\
\hline
\end{tabular}

RT, room temperature. 
Cell death assay

Cell death (apoptosis/necrosis) was determined by Annexin V-FLOUS Apoptosis Kit (Roche, Mannheim, Germany), according to the manufacturer's instructions and as previously described [30]. The percentage of apoptosis/necrosis in the cell population was analysed by flow cytometry (LSRII model, BD Biosciences).

\section{Downregulation of MCT1 and MCT4 expression}

Silencing of MCT1 and MCT4 expression was performed with siRNA (s580 and s17417, respectively, Ambion, Foster City, CA, USA), using an adequate control (scramble siRNA, \#4390843, Ambion, Foster City, CA, USA). Lipofectamine (RNAiMAX 13778075, Invitrogen, Carlsbad, CA, USA) was used as permeabilization agent, according to the manufacturer's instructions.

Drug dose-effect analyses

The combined effect of 5-FU and lactate transport inhibitors (CHC, DIDS and quercetin) was analysed by calculating the combination index ( $\mathrm{CI})$ using the CalcuSyn software (Biosoft, Cambridge, $\mathrm{UK}$ ). When $\mathrm{CI}<1$, the effect is considered as synergistic, $\mathrm{CI}=1$ is additive, and $\mathrm{CI}>1$ antagonistic.

Statistical analysis

Statistical analysis was performed with GraphPad Prism 5 software. Statistical significance was assessed by unpaired $t$-test or one-way ANOVA, followed by Tukey or Dunnett post test. The threshold for significance was considered $p \leq 0.05$.

\section{Results}

CRC and normal colon-derived cell lines express MCT1, MCT4, CD147 and GLUT1 and CRC cells show a more glycolytic profile

Immunocytochemical (Fig. 1A) and Western blot (Fig. 1B) characterization of MCT1, MCT4, CD147 and GLUT1 revealed that all proteins are expressed, mainly at the plasma membrane, in CRC (HCT15, RKO) and normal colon-derived (NCM460) cell lines.

By analysing glucose consumption and lactate production of the different cell lines (Fig. 1C), we observed that the CRC derived cells consume more glucose and produce more lactate over time than NCM460 cells. RKO cells appear to be more glycolytic than HCT15 since they exhibited a higher consumption of glucose and lactate production up to 24 hours.

CHC, DIDS and quercetin impair viability and disrupt the glycolytic phenotype of colorectal carcinoma cells but not of normal colon

CRC and normal (NCM460) cells were treated with the known lactate transport inhibitors CHC, DIDS and quercetin for 24 hours. All tested compounds inhibited in a similar way HCT-15 and RKO cell viability, in a dose dependent-manner, which was not observed for NCM460 cells, within the range of the concentrations used (Fig. 2A).

To better understand the inhibitory effect of CHC, DIDS and quercetin on HCT-15 and RKO cells, the effect on energetic metabolism was assessed. Cells were treated with the correspondent $\mathrm{IC}_{50}$ values determined at 24 hours (HCT-15: $\mathrm{CHC}=10.55 \mathrm{mM}$, DIDS $=0.80 \mathrm{mM}$, quercetin $=142.7 \mu \mathrm{M}$; RKO: $\mathrm{CHC}=9.42 \mathrm{mM}$, DIDS $=0.88 \mathrm{mM}$, quercetin $=121.9 \mu \mathrm{M}$ ), and the extracellular amounts of glucose and lactate were estimated over time. Treatment with $\mathrm{CHC}$ and quercetin significantly decreased glucose consumption and lactate production in HCT-15 cells (Fig. 2B), with reduction in glucose consumption and lactate production already after 4 hours of incubation. In RKO cells, only the treatment with CHC significantly affected glucose consumption (Fig. 2B). Regarding lactate production, $\mathrm{CHC}$ and DIDS treatment showed a significant inhibitory effect in the first 4 hours, with no differences for the remaining incubation periods. Finally, quercetin was the only compound able to inhibit lactate production along time in RKO cells (Fig. 2B).
CHC, DIDS and quercetin impair CRC cell proliferation and induce cell death

As shown in Fig. 2C, all compounds significantly inhibited the proliferation of both cell lines. CHC appears to have a stronger effect on RKO than HCT-15 cells, whereas DIDS and quercetin showed a similar capacity to inhibit proliferation.

Since the effect of the lactate transport inhibitors studied could be attributed not only to inhibition of the proliferative capacity of the cells but also to induction of cell death (apoptosis/necrosis), annexin V/PI staining was assessed. As shown in Fig. 2D, cell death significantly increased after treatment with DIDS for both cell lines, while quercetin significantly increased RKO cell death, with no significant effect on HCT-15 cells. CHC did not increase the percentage of cell death in both cell lines. Among the three compounds tested, DIDS was the most potent in inducing cell death in both CRC cell lines. Moreover, HCT-15 appears to be more sensitive to these lactate transport inhibitors, since a higher overall percentage of dead cells were observed (Fig. 2D).

\section{Downregulation of MCT1 or MCT4 mimics the effects of lactate transport inhibition}

In order to confirm if the results previously observed in CRC cells were a consequence of MCT1/4 activity inhibition, downregulation of MCT1 or MCT4 expression was performed using specific siRNAs in HCT-15 and RKO cells. As shown in Fig. 3A, an effective reduction of MCT1 or MCT4 expression was observed upon MCT1 or MCT4 targeting by siRNAs in both cell lines.

As observed for MCT activity inhibition with CHC, DIDS and quercetin for both CRC cell lines, MCT1 or MCT4 downregulation decreased HCT-15 and RKO cell viability after 24 hours of silencing (Fig. 3B). Likewise, a reduction of the proliferative capacity of these cells was obtained upon silencing of MCT1 or MCT4 (Fig. 3C). Similar to the results obtained with MCT activity inhibition, MCT1 or MCT4 downregulation induced a significant decrease in glucose consumption and lactate production (siMCT1) in HCT-15 cells, while MCT4 silencing resulted in a significant inhibition of lactate production in RKO cells (Fig. 3D).

\section{MCT activity inhibition enhances 5-FU cytotoxic effect in CRC cells}

5-FU decreased HCT-15 and RKO cell biomass in a dose-dependent manner, while no cytotoxic effect was observed on the normal colon cell line, as shown in Fig. 4A. To test if monocarboxylate transport inhibition could potentiate the cytotoxic effect of 5-FU in CRC cells, two approaches were followed: combination and pre-treatment assays. For the combination assay, CRC cells were incubated simultaneously with the lactate transport inhibitors and increasing concentrations of 5-FU during 24 hours. The combination of either CHC or DIDS with 5-FU resulted in an increase of 5-FU cytotoxic effect in CRC cell lines (Fig. 4B). For HCT-15 cells, a synergistic effect was consistently observed only when combining DIDS with 5-FU. For RKO cells, a synergism was observed with the combination of 5-FU with either CHC or DIDS (only for 5-FU higher doses) (Table 3). To assess the effect of lactate transport inhibitors as pre-treatment, CRC cells were pre-incubated with the lactate transport inhibitors (for 24 hours) and then treated with increasing concentrations of 5-FU during 48 hours. As observed in Fig. 4C, pre-incubation of both CRC cell lines with CHC, DIDS and quercetin sensitized cells to 5-FU.

In order to confirm if treatment of CRC cells with 5-FU could enhance the inhibition of glycolytic metabolism observed upon MCT activity inhibition with CHC, DIDS and quercetin, cells were incubated simultaneously with the correspondent $\mathrm{IC}_{50}$ of 5 -FU and the MCT inhibitors for 12 hours and the effects on glucose consumption 
A)

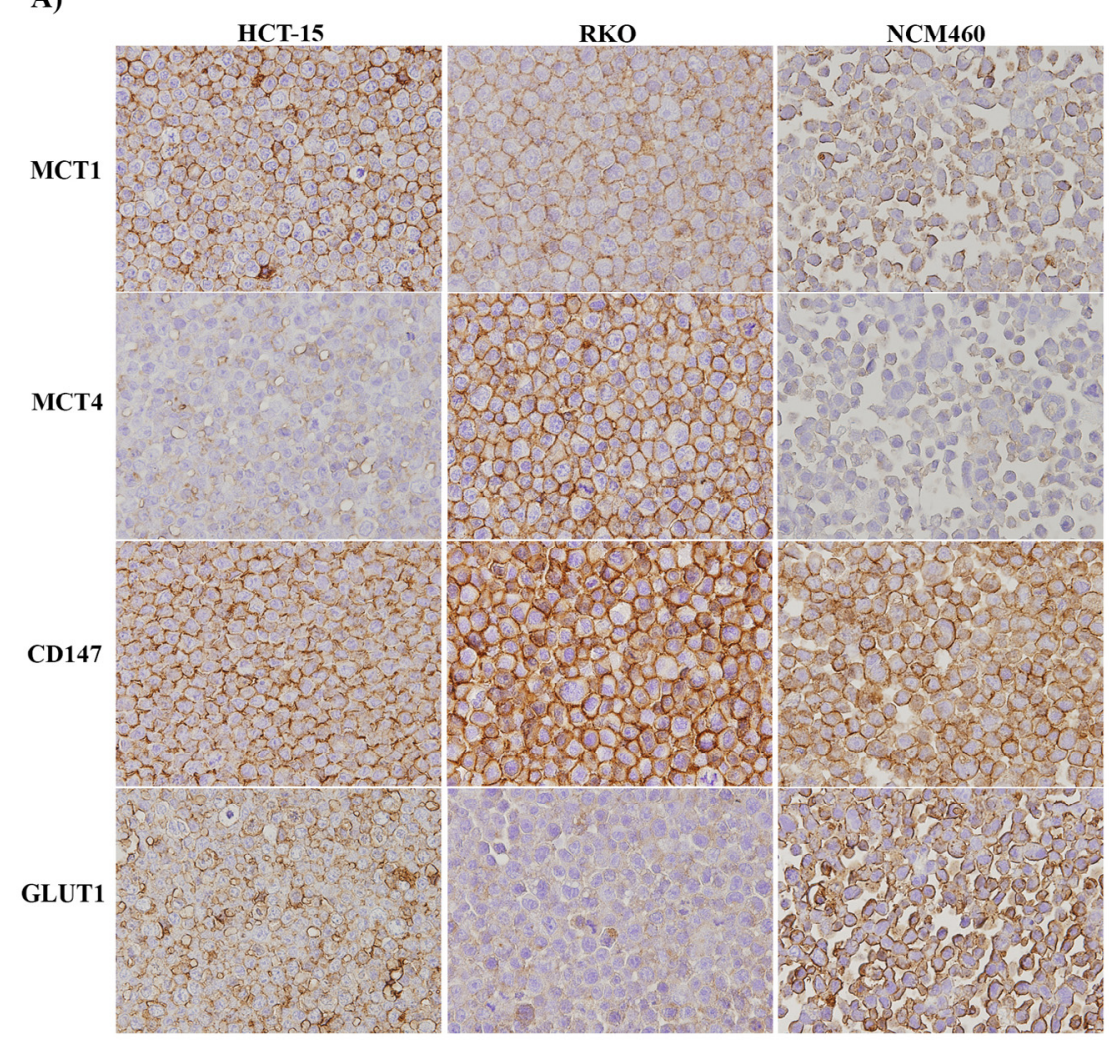

B)

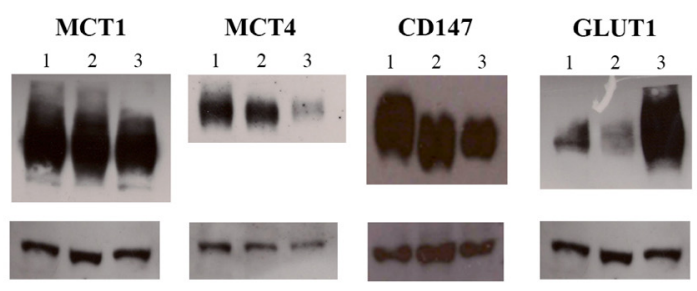

C)
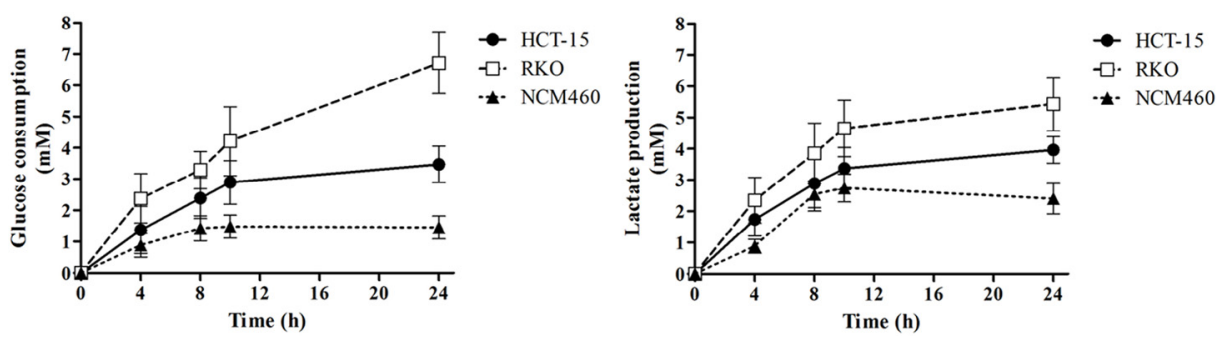

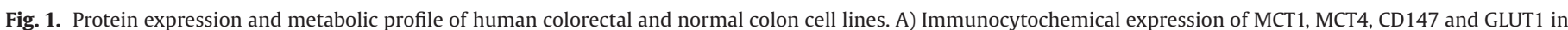

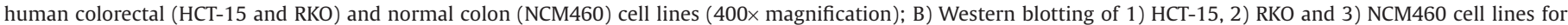

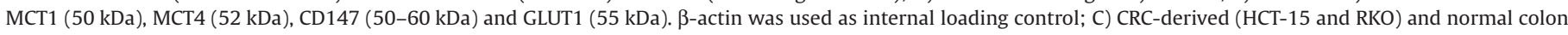

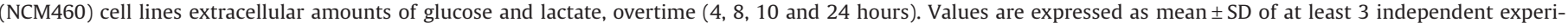
ments, each in triplicate.

and lactate production were assessed. As observed in Fig. 4D, with the exception of glucose consumption in HCT-15 cells, 5-FU per se inhibited the glycolytic metabolism of CRC cells, as a statistically significant decrease in glucose consumption and lactate production was obtained. Importantly, the combination with 5-FU enhanced significantly the inhibitory effect of MCT activity inhibitors on CRC glycolytic metabolism (Fig. 4D).
MCT1/MCT4 expression silencing supports the potentiation of 5-FU cytotoxic effect by lactate transport inhibitors

Aiming to confirm the potentiation of 5-FU cytotoxic effect obtained with MCT activity inhibitors, we combined specific MCT1 or MCT4 downregulation by RNA interference with this chemotherapeutic drug in CRC cell lines. The treatment of HCT-15 and RKO cells, 


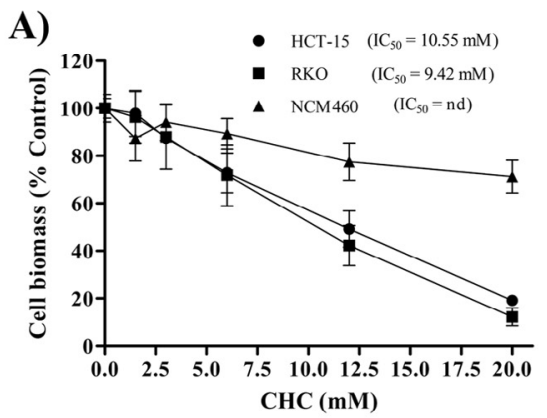

B)

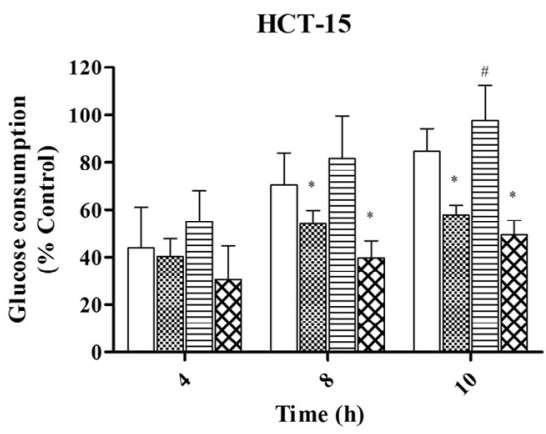

RKO

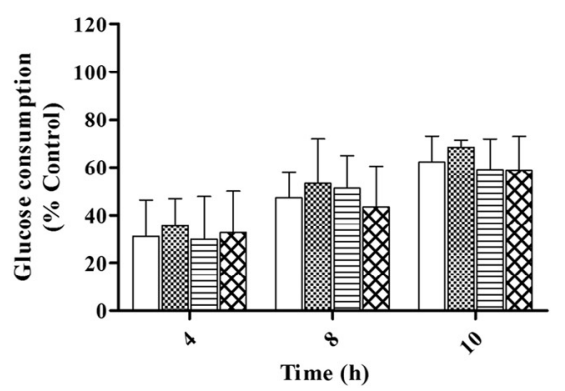

C)

D)

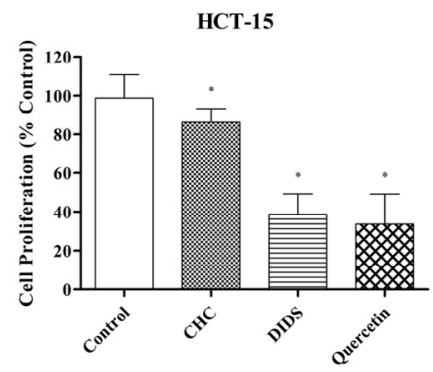

HCT-15

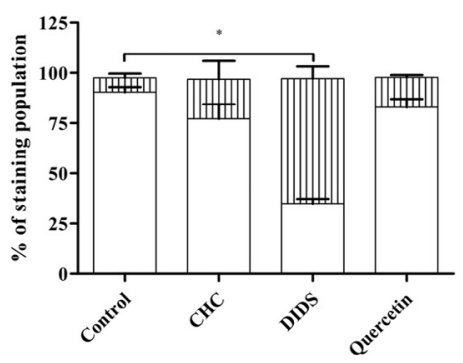

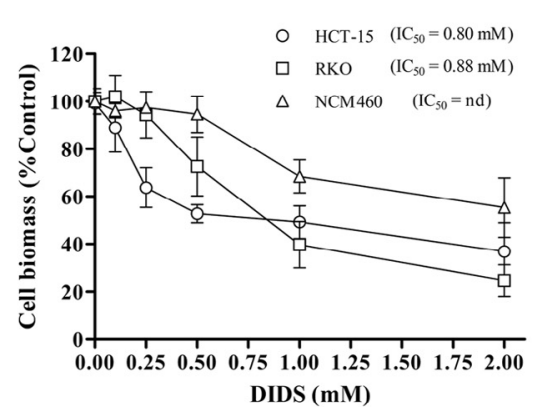

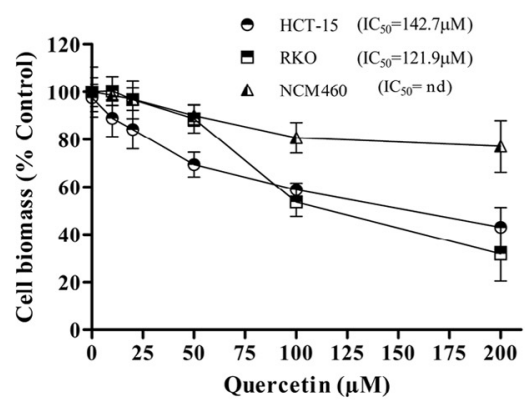

HCT-15
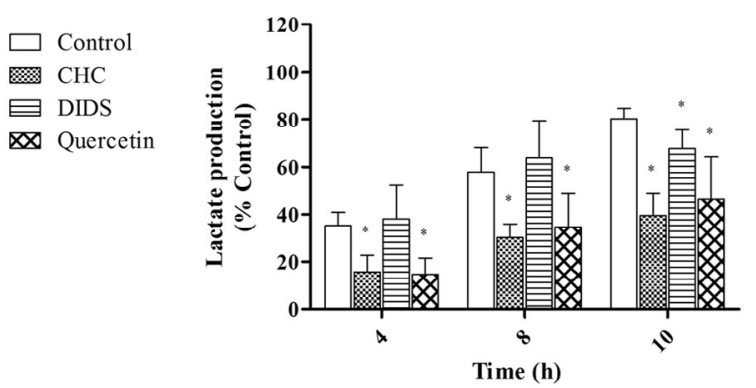

$\square$ Control

CHC

DIDS

Quercetin

RKO
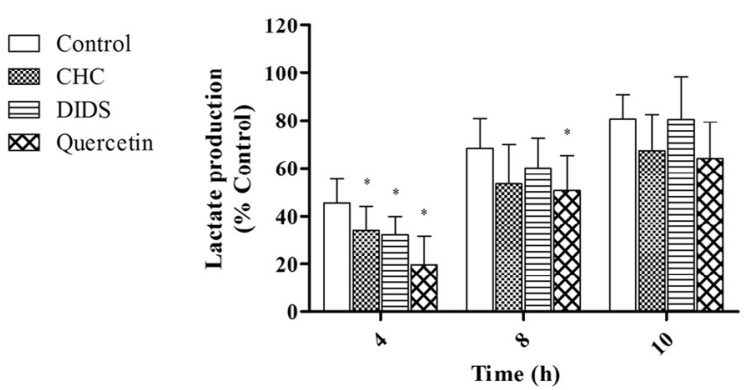

$\square$ Control

ॠ $\mathrm{CHC}$

E DIDS

凶 Quercetin

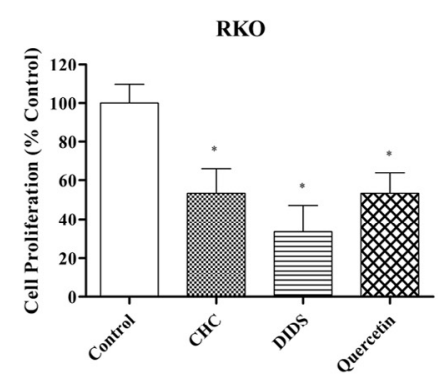

$\square$ Control

$\square$ Control

ख $\mathrm{CHC}$

$\boxminus$ DIDS

Quercetin

$\mathrm{CHC}$

DIDS

Quercetin

RKO

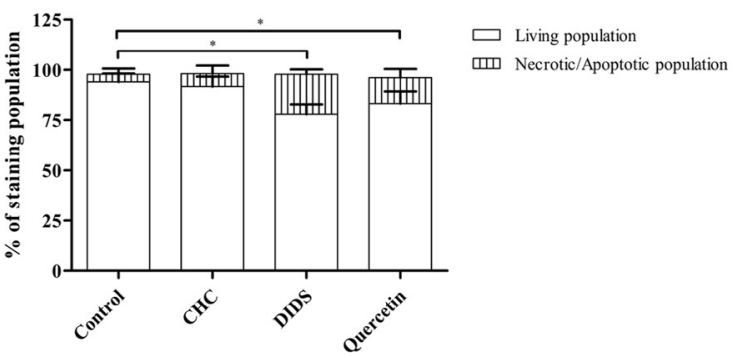

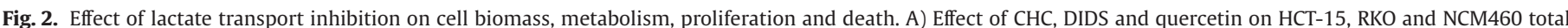

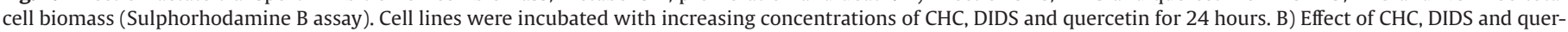

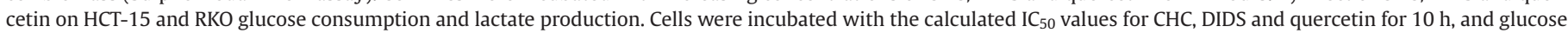

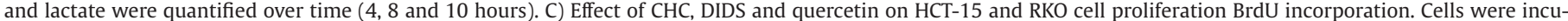

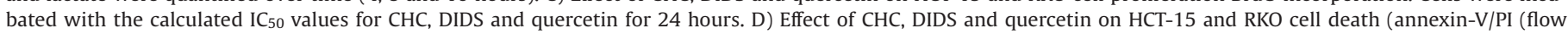

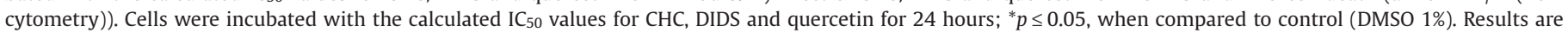
expressed as the mean \pm SD of at least 3 independent experiments, each in triplicate. 
A)

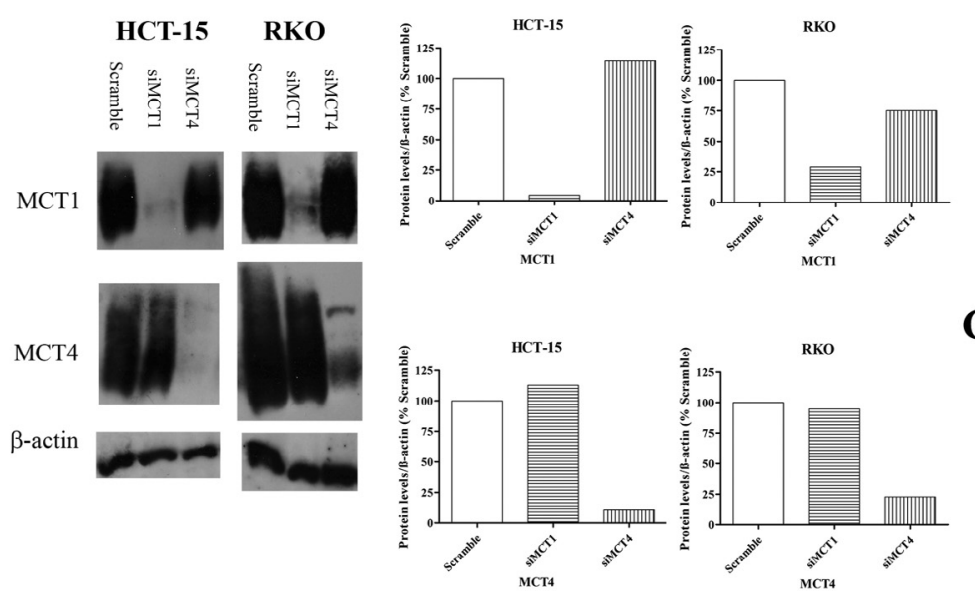

D)

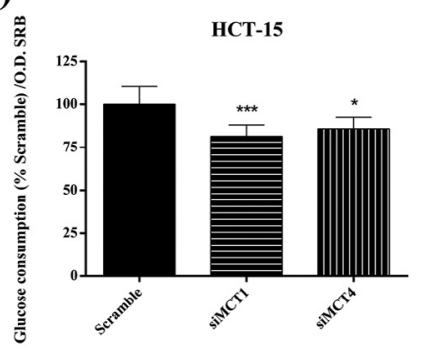

B)

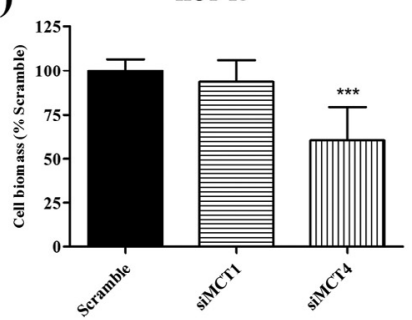

C)

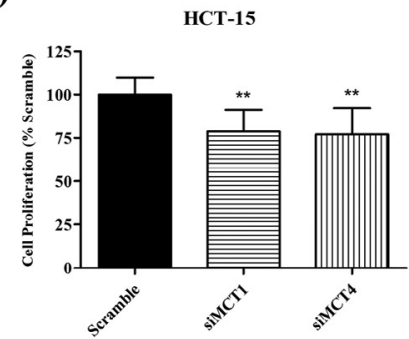

HCT-15

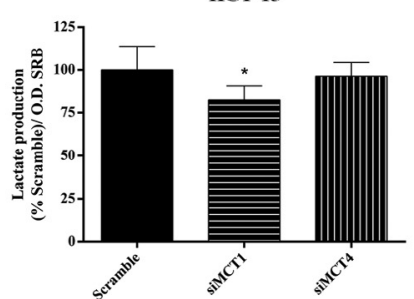

RKO

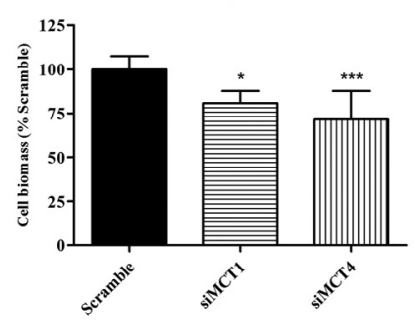

RKO

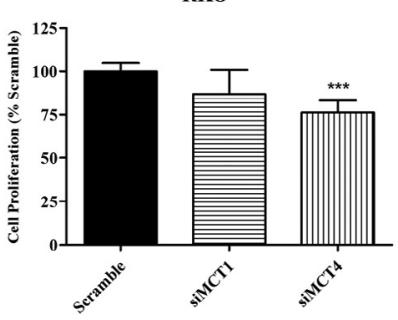

RKO

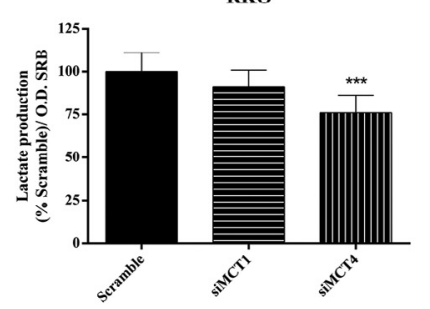

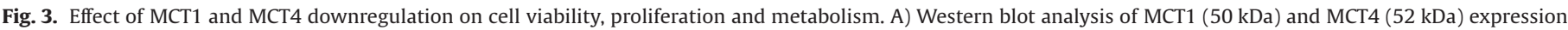

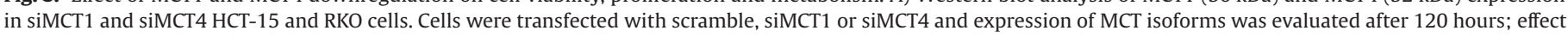

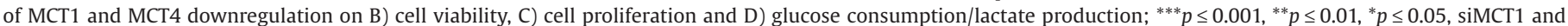
siMCT4 cells compared with scramble. Results represent the mean \pm SD of at least 3 independent experiments, each in triplicate.

Table 3

Combinatory interaction between 5-FU and lactate transport inhibitors (CHC, DIDS and quercetin). $\mathrm{CI}$ was calculated using CalcuSyn 2.0 software.

\begin{tabular}{lrrrrr}
\hline $\begin{array}{l}5-\mathrm{FU}+\mathrm{CHC} \\
(\mathrm{mM})\end{array}$ & $\mathrm{CI}$ & $\begin{array}{l}\text { 5-FU + DIDS } \\
(\mathrm{mM})\end{array}$ & $\mathrm{CI}$ & $\begin{array}{l}\text { 5-FU }(\mathrm{mM})+\text { quercetin } \\
(\mu \mathrm{M})\end{array}$ & $\mathrm{CI}$ \\
\hline $\mathrm{HCT}-15$ & & & & & \\
$0.01+10.55$ & 0.938 & $0.01+0.80$ & 0.699 & $0.01+142.7$ & $>2$ \\
$0.1+10.55$ & 1.024 & $0.1+0.80$ & 0.538 & $0.1+142.7$ & $>2$ \\
$1+10.55$ & 0.983 & $1+0.80$ & 0.440 & $1+142.7$ & $>2$ \\
$10+10.55$ & 1.604 & $10+0.80$ & 0.847 & $10+142.7$ & $>2$ \\
RKO & & & & & $>2$ \\
$0.01+9.42$ & 0.981 & $0.01+0.88$ & 1.045 & $0.01+121.9$ & $>2$ \\
$0.1+9.42$ & 0.986 & $0.1+0.88$ & 1.042 & $0.1+121.9$ & $>2$ \\
$1+9.42$ & 0.640 & $1+0.88$ & 0.779 & $1+121.9$ & $>2$ \\
$10+9.42$ & 0.455 & $10+0.88$ & 0.561 & $10+121.9$ & \\
\hline
\end{tabular}

CI, combination index.

with MCT1 or MCT4 siRNA oligos, in combination with 5-FU, resulted in an evident decrease of 5 -FU $\mathrm{IC}_{50}$ values when compared with the control cells (scramble siRNA) (Fig. 5A). For HCT-15 cell line, the 5 -FU IC 50 value decreased from $5.34 \mathrm{mM}$ in control cells to $2.94 \mathrm{mM}$ and $1.65 \mathrm{mM}$ in cells treated with siMCT1 and siMCT4, respectively. Concerning RKO cells, the $\mathrm{IC}_{50}$ value of 5 -FU for control cells treated with scramble siRNA decreased from $2.11 \mathrm{mM}$ to $0.66 \mathrm{mM}$ and $0.62 \mathrm{mM}$ upon silencing of MCT1 or MCT4, respectively (Fig. 5A).

Furthermore, 5-FU per se led to a significant reduction in lactate production for both CRC-derived cell lines in cells treated with scramble (Fig. 5B1), and upon MCT1 (Fig. 5B2) and MCT4 (Fig. 5B3) silencing. Concerning glucose consumption, only the treatment with 5-FU in HCT-15 silenced for MCT4 led to a significant decrease
(Fig. 5B3). Moreover, treatment of CRC cells with MCT1 or MCT4 siRNAs in combination with 5-FU led to a statistically significant reduction in glucose consumption for both cell lines and a decrease in lactate production in HCT-15 cells upon MCT1 silencing, when comparing to control cells (scramble siRNA) treated with 5-FU (Fig. 5C).

\section{Discussion}

MCTs are essential players in the maintenance of cancer cell metabolism, being promising therapeutic targets [7,13,23-28]; however, the role of MCTs in CRC cell survival and metabolism is still poorly understood. Here, we aimed to characterize the dependence of CRC cells on MCT activity for survival, proliferation and maintenance of energetic metabolism as well as test if MCT inhibition could potentiate the cytotoxic effect of 5-FU, a classical chemotherapeutic agent.

Following our previous findings in human CRC primary tumours [32], we aimed to further dissect the expression of MCTs in CRC derived cells. For that, we evaluated the expression of MCT1, MCT4, CD147 (MCT1/4 chaperone) and GLUT1 (glucose transporter) in CRC (HCT-15 and RKO) and in a normal human colon epithelium (NCM460) derived cell line. The positive expression of both MCT isoforms, CD147 and GLUT1 in the CRC cell lines HCT-15 and RKO, supports the adoption of a glycolytic phenotype. On the other hand, we demonstrated for the first time the expression of MCT1, MCT4 and CD147 in the normal colon cell line NCM460. The expression of MCT1 and its chaperone in normal colon cells was expected [42] since MCT1 is important in the transport of short chain fatty acids (SCFAs) in the colon [43]. SCFAs were demonstrated to protect normal colon mucosa and induce apoptosis of CRC cells in vitro $[43,44]$. 
A)

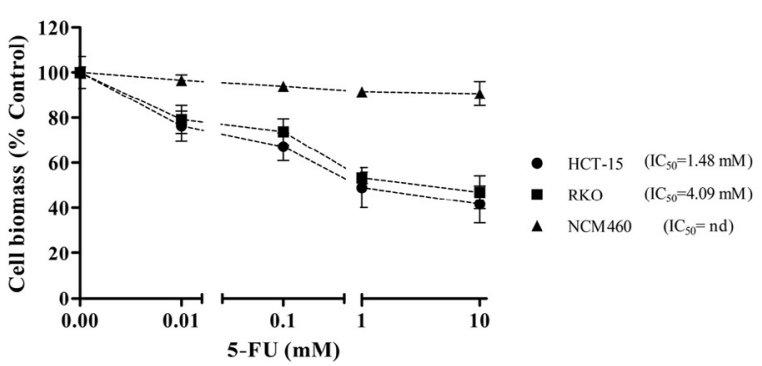

B)

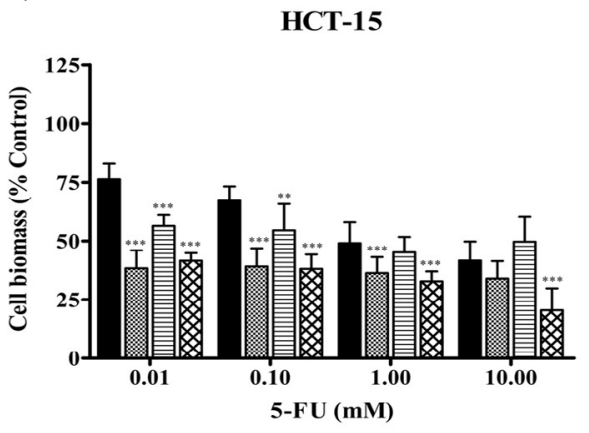

RKO

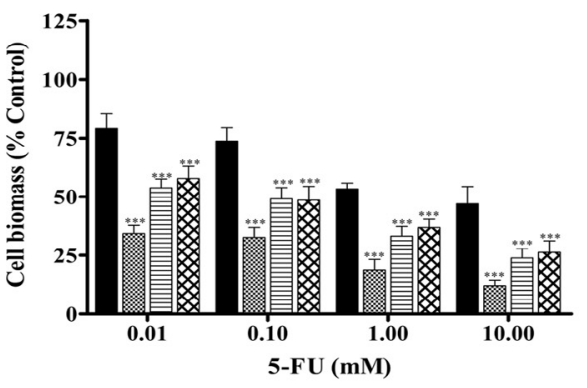

D)

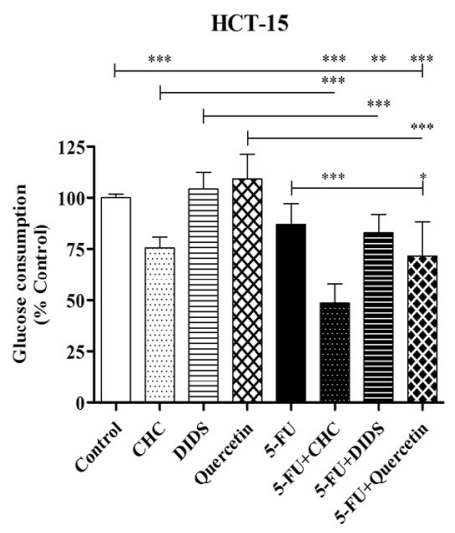

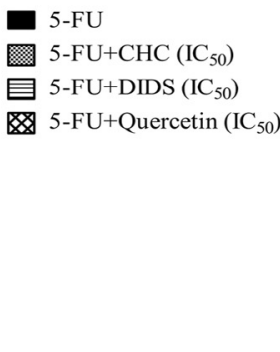

5-FU

$5-\mathrm{FU}+\mathrm{CHC}\left(\mathrm{IC}_{50}\right)$ 5 -FU+DIDS $\left(\mathrm{IC}_{50}\right)$ 5-FU+Quercetin $\left(\mathrm{IC}_{50}\right)$

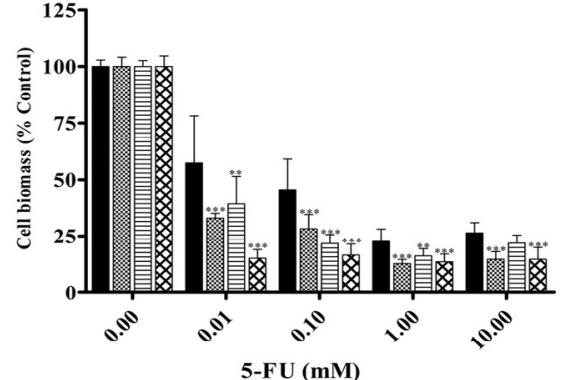

- $5-\mathrm{FU}$

$5-\mathrm{FU}+\mathrm{CHC}\left(\mathrm{IC}_{50}\right)$ 目 $5-\mathrm{FU}+\mathrm{DIDS}\left(\mathrm{IC}_{50}\right)$ $5-\mathrm{FU}+$ Quercetin $\left(\mathrm{IC}_{50}\right)$
5-FU

$5-\mathrm{FU}+\mathrm{CHC}\left(\mathrm{IC}_{50}\right)$

5 -FU + DIDS $\left(\mathrm{IC}_{50}\right)$

5-FU + Quercetin $\left(\mathrm{IC}_{50}\right)$

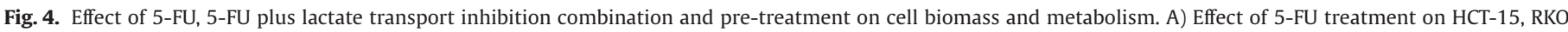

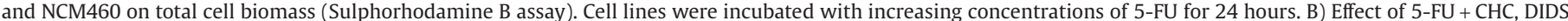

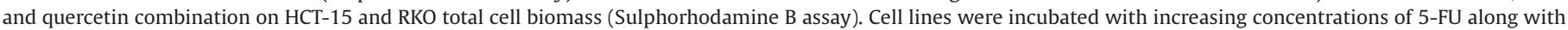

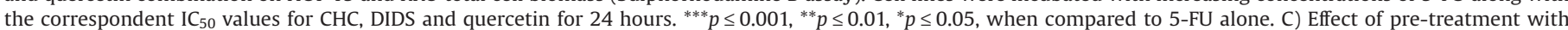

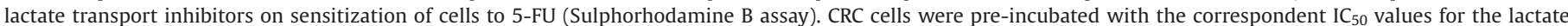

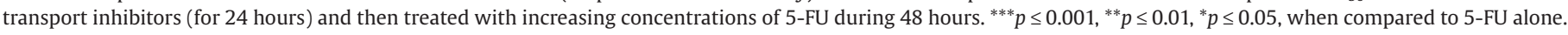

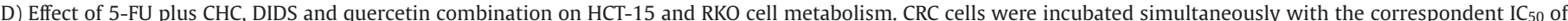

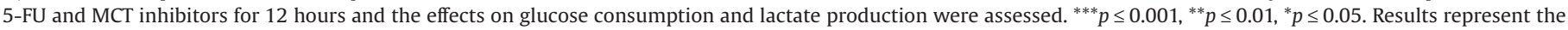
mean \pm SD of at least 3 independent experiments, each in triplicate. 
A)

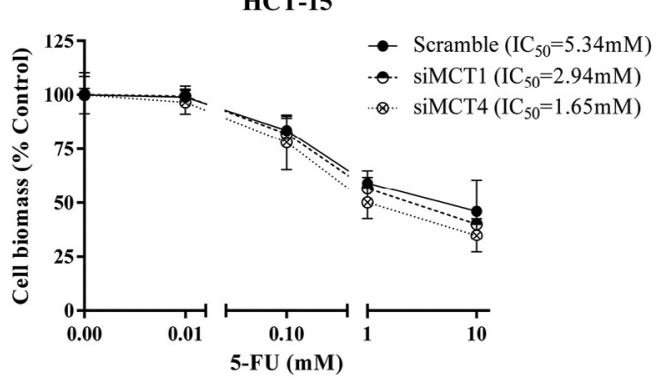

B)
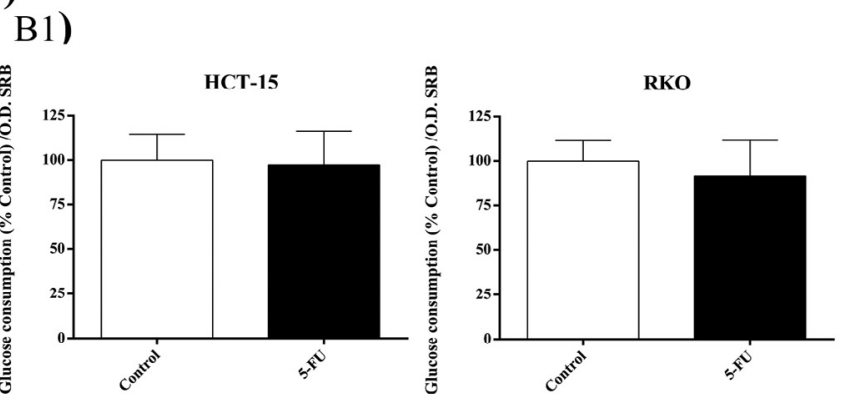

B2)
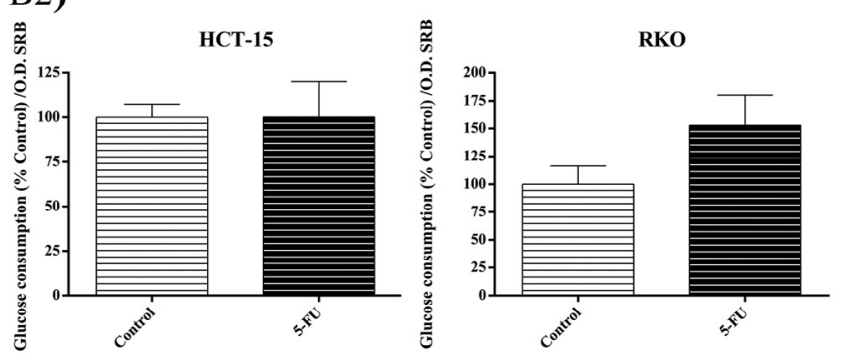

B3)
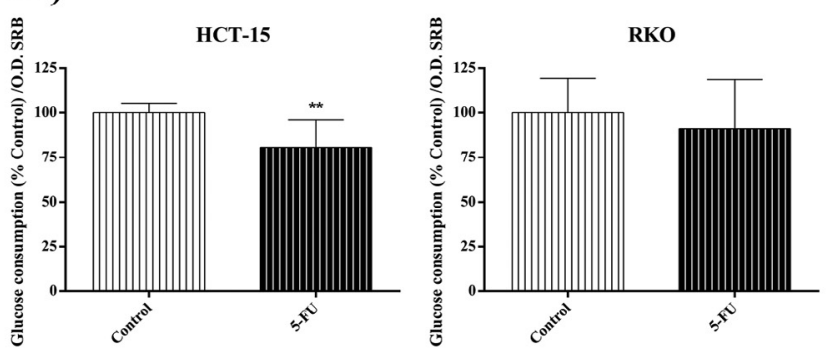

C)
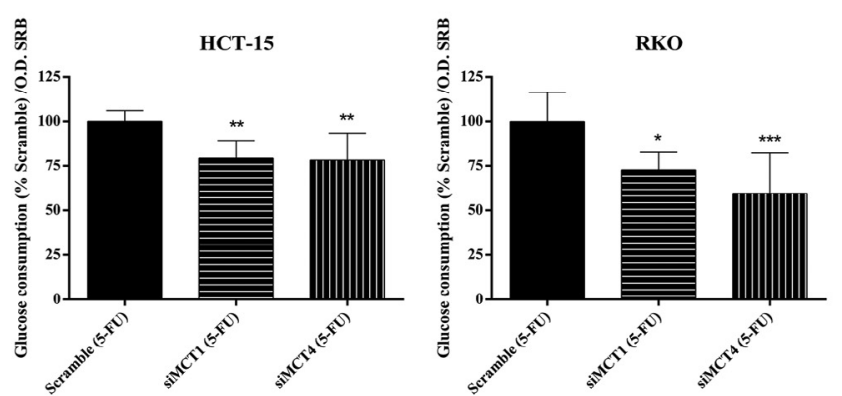
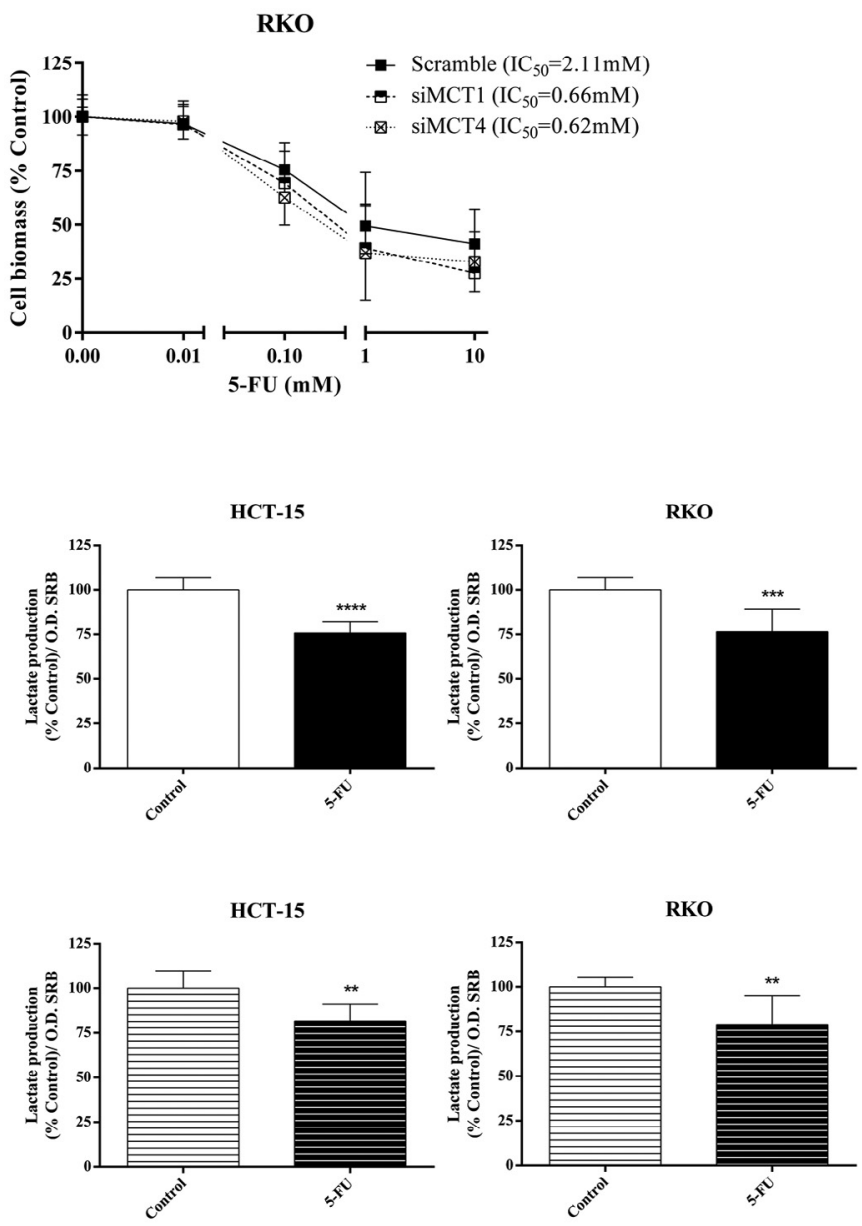

HCT-15

RKO
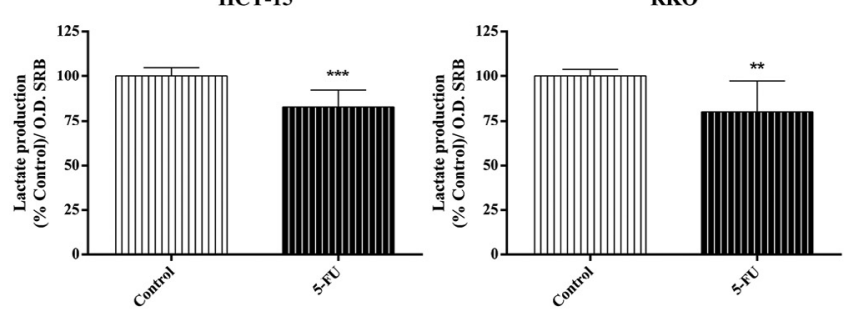

HCT-15

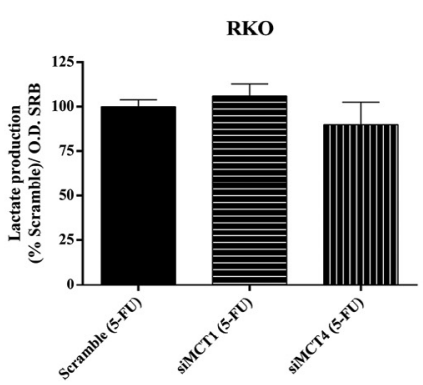

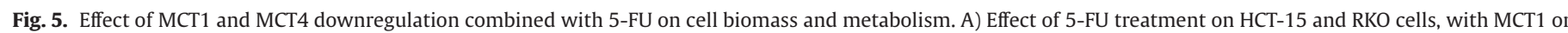

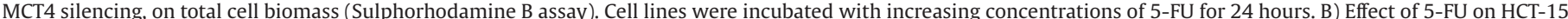

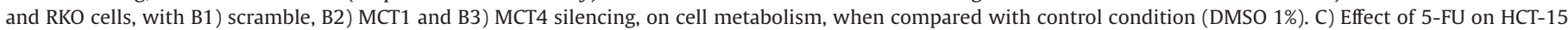

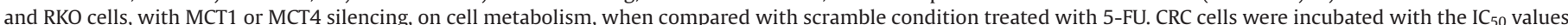

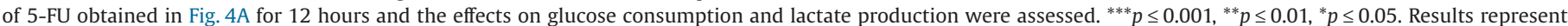
the mean \pm SD of at least 3 independent experiments, each in triplicate. 
In this study, we also addressed the effects of lactate transport inhibition in human CRC cell lines in comparison to normal colon derived cells, using the compounds CHC, DIDS and quercetin, which are known to inhibit lactate transport $[11,13,25,45,46]$. We demonstrated that MCT activity inhibition with these compounds inhibited CRC cells biomass, in a dose-dependent manner and with similar $\mathrm{IC}_{50}$ values, increased cell death and decreased cell proliferation. There was an overall decrease in both glucose consumption and lactate production in HCT-15 cells after treatment with all the compounds. In opposition, no significant alterations in the metabolic rates were found for RKO cells. The reduction of glucose consumption observed is probably due to a negative feedback upon inhibition of lactate transport. Upon MCT activity inhibition, lactate levels within the cell increase and this overload will negatively signal for glucose entrance into the cells. Importantly, the normal colon cell line was less glycolytic and less sensitive to MCT inhibition than CRC cell lines, which is probably related with the lower expression of MCT1 and MCT4 in normal colon cells. This selectivity for CRC cells could constitute a valuable approach to be further exploited in the use of MCT targeting in CRC therapy.

Our results support the hypothesis that MCTs could be promising targets in future CRC therapies and corroborate previous in vitro and in vivo studies in various tumour models using these MCT activity inhibitors [47]. In CRC cells, other authors observed an inhibition of cell survival along with an increase of apoptosis upon treatment with $\mathrm{CHC}$ [48]. The authors linked the alterations observed in cell survival with disruption of lactate efflux and glucose uptake, pH homeostasis, expression of glucose transporters and HIF$1 \alpha$, and generation of nitric oxide [48]. In order to investigate a novel method to enhance radiosensitivity of gliomas, Colen et al. successfully disrupted cell metabolic balance and survival with $\mathrm{CHC}$ [25]. Moreover, it was also shown that, when applied in situ, CHC is nontoxic at concentrations up to $20 \mathrm{mmol} / \mathrm{L}$, in an orthotopic nude rat brain model. More recently, in two glioma cell lines and in an organotypic (brain) slice culture, glioma cell invasion impairment was shown upon lactate efflux inhibition with $\mathrm{CHC}$, with no adverse neurologic effects on control animals [49]. Using both CHC and MCT1 downregulation, antitumour effects were documented without evident toxicity in three different models of animal and human tumours [13]. More recent studies from our group showed an overall decrease in glycolytic metabolism, cell proliferation, migration and invasion, as well as an increase in cell death in glioma [30] and breast cancer cells [29], upon lactate transport inhibition with CHC [29,30] and quercetin [29]. Using oocytes transfected with rat MCT1 or MCT4, Dimmer et al. [46] demonstrated that $500 \mu \mathrm{M}$ DIDS reduced lactate transport by $60 \%$ in rat MCT4, while with superior concentrations (up to $2 \mathrm{mM}$ ) the transporter remained insensitive. In contrast, lactate uptake via MCT1 was completely blocked by DIDS [46].

Taking into account that CHC, DIDS and quercetin are not MCT specific inhibitors [50], it cannot be excluded that the results observed with these compounds are due to inhibition of other cell targets. Thus, we performed downregulation of MCT1 and MCT4 expression with specific siRNAs. Overall, the effects of MCT1 or MCT4 expression inhibition were similar to inhibition of MCT activity, confirming the pivotal role of MCT isoforms 1 and 4 in the maintenance of CRC survival and glycolytic metabolism. As observed in this tumour model, the effects of MCT activity inhibition with CHC and quercetin were corroborated by MCT1 silencing in glioma and breast tumour models $[29,30]$. Additionally, siRNA specific for MCT1 and MCT2 reduced lactate efflux in glioma cells, with concomitant decrease in intracellular $\mathrm{pH}$, and reduction of cell viability with prolonged silencing [24]. Le Floch et al. [51] showed that MCT1/2 inhibition with AR-C155858 (specific MCT1/2 inhibitor) in Rastransformed fibroblasts led to suppression of lactate export, glycolytic rates, and tumour growth. When MCT4 expression was restored, cells became resistant to MCT1/2 inhibition and reestablishment of tumorigenicity was observed. Moreover, in this same study, using human colon adenocarcinoma cells, CD147 gene silencing, alone or in combination with MCT1/MCT4 silencing, reduced glycolytic flux as well as tumour growth [51].

The classical chemotherapeutic drug 5-FU has been largely used in CRC treatment, although there is growing evidence for 5-FU resistance [36] and low efficacy [37]. Several efforts have been made to explore new combination therapies, aiming to enhance the efficacy of 5-FU and reduce side effects. In the present work, we showed for the first time in a CRC model that the use of CHC, DIDS and quercetin potentiates the cytotoxic effect of 5-FU, and this effect was even more evident when cells were pre-treated with the lactate transport inhibitors. These results led us to conclude that these MCT activity inhibitors, by arresting the glycolytic flux through inhibition of lactate transport, turn CRC cells more sensitive to standard therapy. Consequently, pre-treatment of CRC cells with glycolytic inhibitors, namely lactate transport inhibitors, might be a promising strategy for patients with this malignancy. Moreover, we also demonstrated that 5-FU per se arrested glycolytic flux of CRC cells and potentiated the inhibitory effect on glycolysis obtained with MCT activity inhibitors. Importantly, and since these compounds are not MCT specific inhibitors, we downregulated MCT1 and MCT4 expression with specific siRNAs and assessed the effects of combining MCT1 or MCT4 silencing with 5-FU on cell biomass and metabolism. The results obtained with MCT1 or MCT4 silencing corroborated and supported the potentiation of 5-FU cytotoxic effect obtained with lactate transport activity inhibition, namely, we could observe a reduction of 5-FU IC 50 values and an impairment in the glycolytic metabolism.

The beneficial use of metabolic inhibitors, namely MCT inhibitors, in combination with gold-standard therapy, was already described in other studies. Colen et al. [25] observed that pretreatment of glioma cells with $\mathrm{CHC}$ enhanced the sensitivity of these cells to radiotherapy. Moreover, in a cell line derived from colon adenocarcinoma, the authors described an enhanced cytotoxicity of cisplatin together with decreased expression of multidrug resistance regulating genes, when cells were pre-treated with $\mathrm{CHC}$ [48]. Recently, Miranda-Gonçalves et al. showed that $\mathrm{CHC}$ potentiated the effect of temozolomide, the gold standard anti-glioblastoma chemotherapeutic agent, with an important synergistic effect [30].

The mechanism by which 5-FU ultimately benefits from tumour cell glycolytic metabolism arrest, namely lactate transport inhibition, remains unclear. However, recent studies demonstrated an association between 5-FU sensitivity and glucose uptake. In human liver cancer cells, it was observed that 5-FU resistant cells showed higher glucose uptake and lactate production when compared with cells sensitive to 5-FU [52]. By establishing a 5-FU-resistant human colon cancer cell line, Liu et al. [53] demonstrated that resistance to 5-FU was associated with overexpression of GLUT1 and specific inhibition of this glycolytic marker increased the sensitivity of these 5-FU resistant cells to the chemotherapeutic drug [53]. Moreover, in a study using PIK3CA mutant and wild-type gastric cancer cells, the authors described higher resistance to 5-FU when cells were cultured with lower concentrations of glucose [54]. A recent study also reported that inhibition of the glycolytic metabolism by targeting pyruvate dehydrogenase kinase-1 (PDK-1) with the specific inhibitor dichloroacetate was able to re-sensitize gastric cancer cells to 5-FU [55]. Taken together, these studies support the use of glycolytic inhibitors as a pre-treatment or in combination with 5-FU for novel therapeutic protocols to overcome chemotherapeutic resistance.

Overall, our findings showed that MCT activity is important in the survival of CRC and support the use of MCTs as new molecular targets for CRC treatment. Our results also suggest that inhibition of these transporters alone or in combination with 5-FU should be further explored as a novel therapeutic approach for this malignancy in the clinical context. 


\section{Authors' contributions}

RA performed the in vitro studies and wrote the first draft of the manuscript; $\mathrm{CP}$, VMG and HP performed part of the in vitro studies; MPM provided the normal colon-derived cell line and assisted the development of the in vitro studies; AP helped in the design of the study and revised the manuscript; FB conceived and supervised the study and revised the manuscript. All authors read and approved the final manuscript.

\section{Acknowledgements}

Ricardo Amorim was recipient of the fellowships SFRH/BI/51118/ 2010 and SFRH/BD/98002/2013, from Fundação para a Ciência e Tecnologia (FCT, Portugal). This study was supported by the FCT grant ref. PTDC/SAU-FCF/104347/2008, under the scope of "Programa Operacional Temático Factores de Competitividade" (COMPETE) of "Quadro Comunitário de Apoio III" and co-financed by Fundo Comunitário Europeu FEDER. This work was also supported by FEDER through POFC - COMPETE and by FCT through project PEst-OE/BIA/UI4050/2014 and Helena Pereira's fellowship (SFRH/BD/73139/2010).

\section{Conflict of interest}

None.

\section{References}

[1] D. Hanahan, R.A. Weinberg, Hallmarks of cancer: the next generation, Cell 144 (5) (2011) 646-674

[2] R. Stern, et al., Lactate stimulates fibroblast expression of hyaluronan and CD44: the Warburg effect revisited, Exp. Cell Res. 276 (1) (2002) 24-31.

[3] K. Fischer, et al., Inhibitory effect of tumor cell-derived lactic acid on human T cells, Blood 109 (9) (2007) 3812-3819.

[4] V. Ganapathy, M. Thangaraju, P.D. Prasad, Nutrient transporters in cancer: relevance to Warburg hypothesis and beyond, Pharmacol. Ther. 121 (1) (2009) 29-40.

[5] S. Walenta, W.F. Mueller-Klieser, Lactate: mirror and motor of tumor malignancy, Semin. Radiat. Oncol. 14 (3) (2004) 267-274

[6] S. Walenta, T. Schroeder, W. Mueller-Klieser, Lactate in solid malignant tumors: potential basis of a metabolic classification in clinical oncology, Curr. Med. Chem. 11 (16) (2004) 2195-2204.

[7] R.A. Gatenby, R.J. Gillies, Why do cancers have high aerobic glycolysis?, Nat. Rev. Cancer 4 (11) (2004) 891-899.

[8] A.P. Halestrap, The monocarboxylate transporter family - structure and functional characterization, IUBMB Life 64 (1) (2012) 1-9.

[9] A.P. Halestrap, M.C. Wilson, The monocarboxylate transporter family - role and regulation, IUBMB Life 64 (2) (2012) 109-119.

[10] A.P. Halestrap, N.T. Price, The proton-linked monocarboxylate transporter (MCT) family: structure, function and regulation, Biochem. J. 343 (Pt 2) (1999) 281-299.

[11] A.P. Halestrap, D. Meredith, The SLC16 gene family - from monocarboxylate transporters (MCTs) to aromatic amino acid transporters and beyond, Pflugers Arch. 447 (5) (2004) 619-628.

[12] G.L. Semenza, Tumor metabolism: cancer cells give and take lactate, J. Clin. Invest. 118 (12) (2008) 3835-3837.

[13] P. Sonveaux, et al., Targeting lactate-fueled respiration selectively kills hypoxic tumor cells in mice, J. Clin. Invest. 118 (12) (2008) 3930-3942.

[14] N. Draoui, O. Feron, Lactate shuttles at a glance: from physiological paradigms to anti-cancer treatments, Dis. Model Mech. 4 (6) (2011) 727-732.

[15] P. Kirk, et al., CD147 is tightly associated with lactate transporters MCT1 and MCT4 and facilitates their cell surface expression, EMBO J. 19 (15) (2000) 3896-3904

[16] E.A. Marieb, et al., Emmprin promotes anchorage-independent growth in human mammary carcinoma cells by stimulating hyaluronan production, Cancer Res. 64 (4) (2004) 1229-1232.

[17] Y. Tang, et al., Extracellular matrix metalloproteinase inducer stimulates tumor angiogenesis by elevating vascular endothelial cell growth factor and matrix metalloproteinases, Cancer Res. 65 (8) (2005) 3193-3199.

[18] R.C. Poole, A.P. Halestrap, Interaction of the erythrocyte lactate transporter (monocarboxylate transporter 1) with an integral 70-kDa membrane glycoprotein of the immunoglobulin superfamily, J. Biol. Chem. 272 (23) (1997) 14624-14628.

[19] D. Fukumura, et al., Hypoxia and acidosis independently up-regulate vascular endothelial growth factor transcription in brain tumors in vivo, Cancer Res. 61 (16) (2001) 6020-6024.
[20] R. Martinez-Zaguilan, et al., Acidic pH enhances the invasive behavior of human melanoma cells, Clin. Exp. Metastasis 14 (2) (1996) 176-186.

[21] O.K. Schlappack, A. Zimmermann, R.P. Hill, Glucose starvation and acidosis: effect on experimental metastatic potential, DNA content and MTX resistance of murine tumour cells, Br. J. Cancer 64 (4) (1991) 663-670.

[22] M.E. Morris, M.A. Felmlee, Overview of the proton-coupled MCT (SLC16A) family of transporters: characterization, function and role in the transport of the drug of abuse gamma-hydroxybutyric acid, AAPS J. 10 (2) (2008) 311-321.

[23] S.P. Mathupala, et al., Lactate and malignant tumors: a therapeutic target at the end stage of glycolysis, J. Bioenerg. Biomembr. 39 (1) (2007) 73-77.

[24] S.P. Mathupala, P. Parajuli, A.E. Sloan, Silencing of monocarboxylate transporters via small interfering ribonucleic acid inhibits glycolysis and induces cell death in malignant glioma: an in vitro study, Neurosurgery 55 (6) (2004) 1410-1419, discussion 1419

[25] C.B. Colen, et al., Metabolic remodeling of malignant gliomas for enhanced sensitization during radiotherapy: an in vitro study, Neurosurgery 59 (6) (2006) 1313-1323, discussion 1323-4.

[26] J. Fang, et al., The H+-linked monocarboxylate transporter (MCT1/SLC16A1): a potential therapeutic target for high-risk neuroblastoma, Mol. Pharmacol. 70 (6) (2006) 2108-2115.

[27] M.L. Wahl, et al., Regulation of intracellular $\mathrm{pH}$ in human melanoma: potential therapeutic implications, Mol. Cancer Ther. 1 (8) (2002) 617-628.

[28] W. Schneiderhan, et al., CD147 silencing inhibits lactate transport and reduces malignant potential of pancreatic cancer cells in in vivo and in vitro models, Gut 58 (10) (2009) 1391-1398.

[29] F. Morais-Santos, et al., Differential sensitivities to lactate transport inhibitors of breast cancer cell lines, Endocr. Relat. Cancer 21 (1) (2014) 27-38.

[30] V. Miranda-Gonçalves, et al., Monocarboxylate transporters (MCTs) in gliomas: expression and exploitation as therapeutic targets, Neuro-Oncol. 15 (2) (2013) $172-188$.

[31] M.I. Koukourakis, et al., Comparison of metabolic pathways between cancer cells and stromal cells in colorectal carcinomas: a metabolic survival role for tumor-associated stroma, Cancer Res. 66 (2) (2006) 632-637.

[32] C. Pinheiro, et al., Increased expression of monocarboxylate transporters 1, 2, and 4 in colorectal carcinomas, Virchows Arch. 452 (2) (2008) 139-146.

[33] Y. Nakayama, et al., Prognostic significance of monocarboxylate transporter 4 expression in patients with colorectal cancer, Exp. Ther. Med. 3 (1) (2012) 25-30.

[34] Y. Gotanda, et al., Expression of monocarboxylate transporter (MCT)-4 in colorectal cancer and its role: MCT4 contributes to the growth of colorectal cancer with vascular endothelial growth factor, Anticancer Res. 33 (7) (2013) 2941-2947.

[35] F. Hollande, J. Pannequin, D. Joubert, The long road to colorectal cancer therapy: searching for the right signals, Drug Resist. Updat. 13 (1-2) (2010) 44-56.

[36] D.B. Longley, D.P. Harkin, P.G. Johnston, 5-Fluorouracil: mechanisms of action and clinical strategies, Nat. Rev. Cancer 3 (5) (2003) 330-338.

[37] Modulation of fluorouracil by leucovorin in patients with advanced colorectal cancer: evidence in terms of response rate. Advanced Colorectal Cancer Meta-Analysis Project, J. Clin. Oncol. 10 (6) (1992) 896-903.

[38] S. Terstriep, A. Grothey, First- and second-line therapy of metastatic colorectal cancer, Expert Rev. Anticancer Ther. 6 (6) (2006) 921-930.

[39] M. Degirmenci, et al., Efficacy and safety of bevacizumab plus capecitabine and irinotecan regimen for metastatic colorectal cancer, Med. Oncol. 27 (3) (2010) 585-591.

[40] M. Koopman, et al., A review on the use of molecular markers of cytotoxic therapy for colorectal cancer, what have we learned?, Eur. J. Cancer 45 (11) (2009) 1935-1949.

[41] N. Silvestris, et al., Update on capecitabine alone and in combination regimens in colorectal cancer patients, Cancer Treat. Rev. 36 (Suppl. 3) (2010) S46-S55.

[42] R.C. Poole, A.P. Halestrap, Transport of lactate and other monocarboxylates across mammalian plasma membranes, Am. J. Physiol. 264 (4 Pt 1) (1993) C761-C782.

[43] M.A. Cuff, D.W. Lambert, S.P. Shirazi-Beechey, Substrate-induced regulation of the human colonic monocarboxylate transporter, MCT1, J. Physiol. 539 (Pt 2) (2002) 361-371.

[44] C. Marques, et al., Acetate-induced apoptosis in colorectal carcinoma cells involves lysosomal membrane permeabilization and cathepsin D release, Cell Death Dis. 4 (2013) e507.

[45] Q. Wang, M.E. Morris, Flavonoids modulate monocarboxylate transporter-1mediated transport of gamma-hydroxybutyrate in vitro and in vivo, Drug Metab. Dispos. 35 (2) (2007) 201-208.

[46] K.S. Dimmer, et al., The low-affinity monocarboxylate transporter MCT4 is adapted to the export of lactate in highly glycolytic cells, Biochem. J. 350 (Pt 1) (2000) 219-227.

[47] F. Baltazar, et al., Monocarboxylate transporters as targets and mediators in cancer therapy response, Histol. Histopathol. 29 (12) (2014) 1511-1524.

[48] A. Kumar, S. Kant, S.M. Singh, Targeting monocarboxylate transporter by alpha-cyano-4-hydroxycinnamate modulates apoptosis and cisplatin resistance of Colo205 cells: implication of altered cell survival regulation, Apoptosis 18 (12) (2013) 1574-1585.

[49] C.B. Colen, et al., Metabolic targeting of lactate efflux by malignant glioma inhibits invasiveness and induces necrosis: an in vivo study, Neoplasia 13 (7) (2011) 620-632

[50] A.P. Halestrap, The SLC16 gene family - structure, role and regulation in health and disease, Mol. Aspects Med. 34 (2-3) (2013) 337-349.

[51] R. Le Floch, et al., CD147 subunit of lactate/H+ symporters MCT1 and hypoxiainducible MCT4 is critical for energetics and growth of glycolytic tumors, Proc. Natl. Acad. Sci. U.S.A. 108 (40) (2011) 16663-16668. 
[52] J.X. Jiang, et al., Overexpression of microRNA-125b sensitizes human hepatocellular carcinoma cells to 5-fluorouracil through inhibition of glycolysis by targeting hexokinase II, Mol. Med. Rep. 10 (2) (2014) 995-1002.

[53] W. Liu, et al., Overcoming 5-Fu resistance of colon cells through inhibition of Glut1 by the specific inhibitor WZB117, Asian Pac. J. Cancer Prev. 15 (17) (2014) 7037-7041.
[54] B. Bhattacharya, et al., Increased drug resistance is associated with reduced glucose levels and an enhanced glycolysis phenotype, Br. J. Pharmacol. 171 (13) (2014) 3255-3267.

[55] Y. Xuan, et al., Dichloroacetate attenuates hypoxia-induced resistance to 5 -fluorouracil in gastric cancer through the regulation of glucose metabolism, Exp. Cell Res. 321 (2) (2014) 219-230. 